\title{
Exploration Results, Exploration Targets, and Mineralisation
}

\author{
by T.R. Marshall
}

\section{Synopsis}

While the original intent of all of the international reporting codes was to regulate the Public Reporting of Mineral Resources and Mineral Reserves only, many jurisdictions have seen the need to provide guidance for the reporting of Exploration Targets, which are the lifeblood of junior exploration and mining companies and private operators alike. In harmony with this trend, the SAMREC Code 2016 has greatly expanded the issues surrounding Exploration Results and Exploration Targets and has also introduced the concept of Mineralisation. This document seeks to clarify the concepts and definitions and to assist in clearing misconceptions before they arise. A number of case-study examples are presented in order to illustrate the differences between Exploration Targets that are purely conceptual and those which may be identified as Mineralisation.

Keywords

Public Reporting, Resource classification, Exploration Results, Exploration Targets, Mineralisation. the definition of 'Public Reports' has been expanded significantly to include all reports that may be of use to investors and potential investors.

This migration appears to be, partially, in recognition of the increasing role played by junior exploration and mining companies and their need to report on strategic exploration targets for continued financial support. In addition to the needs of junior companies, large mining companies need to continuously assess long-term development opportunities in the exploration areas surrounding their operations (Mullins et al., (2014). The objectives of these programmes are to develop a thorough understanding of the mineral inventory so that the full mineral endowment potential of an area can be considered under multiple scenarios and long-term investment decisions taken to optimize the development potential of the province. It was argued that such objectives require a consistent approach to evaluating the nature and extents of potentially economic mineralisation. While guidelines such as the JORC Code (and, by extension, the SAMREC Code) adequately address this for Public Reporting purposes, internal strategic decisions often require a less conservative, but similarly rigorous, approach so that projects and increasingly competitive budgets can be prioritized before all of the information needed for formal resource estimation and classification is available.

Similar to other codes, the 2007/2009 SAMREC Code did not place much emphasis on the definition of Mineral Resources, beyond the statement that there were to be reasonable expectations for eventual economic extraction. Apart from recognizing that it is common practice for a company to comment on and discuss its exploration in terms of target size

* Explorations Unlimited, South Africa.

(c) The Southern African Institute of Mining and Metallurgy, 2017. ISSN 2225-6253. This paper was first presented at the SAMREC/SAMVAL Companion Volume Conference 'An Industry Standard for Mining Professionals in South Africa', 17-18 May 2016, Emperors Palace, Johannesburg 


\section{Exploration Results, Exploration Targets, and Mineralisation}

and type, guidelines for anything in the pre-resource space were even more vague and, consequently, reporting of exploration results, exploration targets, mineralisation, and inventory became highly suspect in terms of credibility. The emerging importance of Exploration Results as a defined term was, however, seen in the fact that an entire column in Table 1 of the SAMREC Code ('Exploration Results (A)') was dedicated to the discussion of exploration data and information, where applicable.

'Exploration target' became a sack term for anything that did not meet the requirements of a Mineral Resource and included everything from pure conceptual models to properties where the amount of data and/or the level of confidence in the results fell just short of 'Resource'. Since it is not a Resource, according to the Codes an Exploration Target could not form part of a Mineral Resource statement or tabulation, nor be included in any techno-economic assessment, however preliminary. An unintended consequence of the inclusion of both early and more advanced reconnaissance-stage exploration programmes was that many that of the more advanced reconnaissance-stage properties were shoehorned into the Inferred Resource category because that was the lowest classification that credited the company with having done any exploration on the target property.

The latest versions of the JORC, PERC, and SME codes all define an Exploration Target as 'a statement or estimate of the exploration potential of a mineral deposit in a defined geological setting where the statement or estimate, ... relates to mineralisation for which there has been insufficient exploration to estimate Mineral Resources' (same or similar wording). Both JORC and PERC note that all disclosures of an Exploration Target should clarify whether the target is based on actual exploration results completed or on proposed exploration programmes yet to commence, implying that Exploration Targets can be both conceptual or advanced. The provisions of SME indicate that only properties where actual exploration results have been obtained can be described as Exploration Targets. Although CIM makes no mention of either of the terms Exploration Results or Exploration Target, the National Instrument 43-101 Companion Policy of 2011 gives limited guidelines on what might constitute such information and how it may be reported publicly in a manner that does not misrepresent the potential prospectivity of the property.

It is in recognition of these matters that the SAMREC Code 2016 has greatly expanded the issues surrounding Exploration Results and Exploration Targets, and has also introduced the concept of Mineralisation (as opposed to mineralisation as a geological term, which SAMREC defines as 'The process or processes by which a mineral or minerals are introduced into a rock, resulting in a potentially valuable deposit. It is a general term, incorporating various types, e.g. fissure filling, impregnation, replacement, etc.'). The Code has also seen the migration from reports that deal with purely listed entities to any document that may find its way into the public domain, and even includes statements on social media. In addition to the requirements of the various securities exchanges with respect to public reporting by listed companies of all sizes, industry best practice strongly recommends that reports compiled for 'private' companies also be compiled in accordance with the SAMREC Code - the primary argument being that investors in non-listed entities deserve the same level of professionalism in reporting and valuation standards as for listed companies. In recent years there has been an upsurge in the number of Public Reports associated with non-listed companies. The reasons for this are many and varied, but the most common involve the many private companies that are looking to obtain finance for very early-stage exploration projects from financial institutions (such as the Industrial Development Corporation, banks, and/or mining funds), from established (listed) exploration and mining companies, or from high-wealth individuals. In most of these situations, the potential investor requires a Competent Person's Report (CPR) before being willing to commit to commercial terms.

This paper seeks to clarify the thought processes by the Exploration Results subcommittee of the SAMREC Working Group in developing the definitions and concepts integral to the pre-resource space and to assist in clearing misconceptions before they arise.

\section{Exploration Results}

The 2016 SAMREC Code (Clause 20) defines Exploration Results as data and information generated by exploration programmes that may be of use to investors, but which do not form part of a declaration of Mineral Resources or Mineral Reserves. The reporting of such information is common in the early stages of exploration when the quantity of data available is generally not sufficient to allow any reasonable estimates of Mineral Resources. What is vitally important in the reporting of such Exploration Results is that they must not be presented in such a manner so as to unreasonably imply that potentially economic mineralisation has been discovered.

Reports of Exploration Results must contain sufficient information to allow for a considered and balanced judgement of their significance and the reporting should be structured to include both positive and negative relevant data and information relating to the mineral property. The overriding emphasis is on balanced reporting, providing relevant information relating to prospecting activity that has taken place on the property of interest.

Such Exploration Results may include survey, geological, geophysical, geochemical, sampling, drilling, trenching, analytical testing, assaying, mineralogical, metallurgical, and other data and information, where available. Exploration Results may also include historical data/information as well as data/information from adjacent or nearby properties, if the $\mathrm{CP}$ can provide justification for its inclusion. Such justification must include at least some physical evidence of assumed continuity of the mineralisation on the property of interest.

With the rise of the junior exploration company, it has become common practise to comment on and discuss Exploration Results in terms of size and type, even at a very early stage of prospecting, before formal Mineral Resources have been identified. There is a long history of mining projects where the mineral endowment of a district or province is underestimated and careful consideration of the full potential for economic mineralisation in the early stages of assessment could have significantly improved development decisions and long-term profitability (Mullins et al., 2014). Likewise, examples of overestimating the potential size of a mineral district have been equally disastrous for shareholder 


\section{Exploration Results, Exploration Targets, and Mineralisation}

value. Historically, this is where many (listed and private) companies have misused and abused reporting standards, resulting in, at best, the obfuscation of the situation so as to imply better results than actually exist and, at worst, the gross misrepresentation of the potential of projects (probably the most infamous example of this in modern times is the Bre-X fiasco in 1995-1997).

\section{Exploration Targets}

The term 'exploration target' in the 2007/2009 SAMREC Code (Clause 20) had no formal definition, but was included as a way of reporting Exploration Results that might be of interest to investors. The governing principles of reporting exploration targets was that any statement referring to potential quantity, quality, and content of the target was to be expressed as ranges (to emphasize the lack of confidence in the data) and that they were to be accompanied by various cautionary statements.

The definition of the term 'Exploration Target' in Clauses $21 / 22$ of the 2016 SAMREC Code has retained these essential elements. In harmony with other international codes, Exploration Target is defined as a statement, or estimate, of the exploration potential of a mineral deposit in a defined geological setting where the statement or estimate, quoted as a range of tons and a range of grade or quality, relates to mineralisation for which there has been insufficient exploration to estimate Mineral Resources.

The essence of an Exploration Target is that, at one extreme, it can refer to a concept of mineralisation. It does not necessarily require that any mineralisation be identified or even that the company has identified specific properties for acquisition. A (conceptual) Exploration Target, therefore, need not, imply reasonable prospects for eventual economic extraction (RPEEE). Notwithstanding, there must be a likelihood that this exploration target occurs in an area of geological prospectivity for that commodity and mineralisation type.

For example, a diamond company might target a property located on the Kaapvaal Craton in a region where kimberlite pipes are known to occur. The known kimberlite cluster may or may not include a pipe that is currently being mined, or that was mined in the past. The Exploration Target might be associated with the occurrence of an indicator mineral anomaly or a geophysical anomaly, or perhaps artisanal miners are recovering alluvial diamonds downstream from the property.

At the other extreme, an Exploration Target may refer to a specific area in a property held under licence that has been subject to an advanced reconnaissance exploration programme, but where either the amount of data or the level of confidence in the data is insufficient for classification as a Mineral Resource or where RPEEE have not yet been established for the specific property.

So, the company in the example above might have drilled a number of holes into one of the geophysical anomalies and identified the presence of kimberlite. The systematic drilling was able to identify an initial volume of some $20 \mathrm{Mm}^{3}$ of kimberlite down to a depth of $60 \mathrm{~m}$. Each intersection may have been sampled for microdiamonds which indicated potential grades in the order of 30-40 carats per hundred tons (the bulk density was assumed from a regional average average). However, to date, only 25 macrodiamonds have been recovered from the initial bulk sampling programme. While this data will fall short of allowing the project being classified as a Resource, it can be classified as an Exploration Target (with identified Mineralisation).

In terms of Clause 21, anything classified as an Exploration Target must not be expressed so as to be misrepresented or misconstrued as an estimate of a Mineral Resource or Mineral Reserve. Details of the Exploration Target may not form part of a Resource statement or be included in a tabulation of Mineral Resources or Mineral Reserves. Exploration Targets may not be included in a Technical Study (at Scoping, Pre-Feasibility, or Feasibility level) and may not be converted to Mineral Reserves (Clauses 21, 43-46). They may not be included in economic assessments or discounted cash flow (DCF) models, nor be included in valuations based on Income Approaches. Given the levels of uncertainty surrounding the supporting data, the quantity (volume or tonnage) or quality (grade and value) of an Exploration Target may not be reported as a headline statement' in a Public Report (Clause 22).

When discussing Exploration Targets, the CP must clearly describe the rationale for such selection, including the geological model on which it is based. Any statement referring to potential quantity, quality, and content, as appropriate, must be substantiated and include a detailed explanation of the basis for the statement. This must be followed by a proximate statement, with the same prominence, that the potential quantity, quality, and content, as appropriate, are conceptual in nature, that there has been insufficient exploration to define a Mineral Resource and that it is uncertain if further exploration could result in the determination of a Mineral Resource.

'Same prominence' is defined as the same font type and size and 'proximate location' is defined as the cautionary statement being included in the same paragraph as, or immediately following, the reported statement. The cautionary statement may not be by way of a footnote, nor will a general disclaimer elsewhere in the disclosure document satisfy this requirement. This cautionary statement must, further, be made each time the statement of potential quantity, quality, and content is presented.

Any statement referring to quantity and quality must reflect the lack of reliable data. Where the statement includes information relating to ranges of tonnages and grades, these must be represented as approximations. The conceptual nature of the statements must be expressed either through the use of 'order of magnitude', including appropriate descriptive terms (such as 'approximately', 'in the order of', etc.) or as 'ranges', which is defined as the variation between the lowest and highest relevant Exploration Results - the use of ranges in this context has no statistical relevance.

Estimates of potential quantity and quality should, preferably, be made in terms of volume (or area) and not mass/tonnage. If, however, target tonnages are reported, then the preliminary estimates, or the basis of assumptions, made for bulk density must be stated. The explanatory text must include a description of the process used to determine the grade and tonnage ranges describing the Exploration Target or Mineralisation.

Appropriate rounding should be used to express the level of uncertainty of the estimates. By way of example, 'approximately one to two million tons at a grade of 3-5\% Cu' or 'an Exploration Target of more than 100 million tons of 


\section{Exploration Results, Exploration Targets, and Mineralisation}

coal in excess of $16 \mathrm{MJ} / \mathrm{kg}$ for power generation markets' would be acceptable, but not ' $2 \pm 0.2$ million tons'. When estimates are quoted, statements of both quantity and quality must be provided. It is not permissible to quote one without the other.

In addition, any discussion of Exploration Targets must include the intended exploration work programme to explore for the target, detailing the extent of the proposed exploration activities, the planned timeframe, and the anticipated costs. Public Reporting of an Exploration Target shall not be done unless supported by exploration. Without an explicit exploration work programme, Public Reporting of an Exploration Target must be regarded as being solely speculative (Clause 21). Clause 20 further notes that in discussions of Exploration Targets on properties adjacent to, or nearby, properties of known mineralisation, at least some physical evidence of assumed continuity of the mineralisation on the property of interest must be presented by the $\mathrm{CP}$.

\section{Mineralisation}

A new term, Mineralisation, (Clause 21/22) has been introduced (as a subset of Exploration Target) to deal with the situation where the Exploration Target is no longer purely conceptual, but where actual data has been obtained on the property and where mineralisation of significance (as opposed to a mineral occurrence) has been identified (see example above). Mineralisation refers to the situations where insufficient data has been acquired to estimate a Mineral Resource, where the existing data is of insufficient confidence to allow the classification of a Mineral Resource, or where RPEEE have not yet been demonstrated. In this respect, the concept of Mineralisation is similar to the term 'deposit' in the previous SAMREC Codes. It can be roughly correlated with the concept of Inventory Coal (SANS 10320, 2nd Edition - note, however, that the term 'Inventory Coal' is not recognized by the SAMREC 2016 Code, nor shall it to be included or presented in Public Reports).

The term Mineralisation has been introduced in deference to the proliferation of both private and junior exploration companies whose continued financial backing depends on the presentation of exploration results in the public domain. It was noted that, unless terminology was introduced and strictly controlled, then the current Resource definitions (especially the Inferred Mineral Resource category) would be adulterated by individuals/companies seeking the highest classification for their projects. It would not be sufficient to simply prohibit the reporting of anything that did not meet the requirements of the 'Resource' definition - the necessity to publicize results would still result in further abuse of the codes.

For an Exploration Target where Mineralisation has been identified based on Exploration Results, a summary of the relevant exploration data/information and the nature of the results should also be presented, including a disclosure of the current drill-hole or sampling spacing and relevant plans or sections. In any subsequent upgraded or modified statements on the Exploration Target, the CP should discuss any material changes to potential scale or quality arising from completed exploration activities.

Typically, the phases of an exploration programme, and the subsequent classification, can be defined by the activities carried out in that phase (Table I). Depending on the mineral commodity and/or style of mineralisation, the activities undertaken in each exploration phase may differ significantly. The list included in this table is not meant to be exhaustive and is for illustrative purposes only.

Table I

Examples of activities in different exploration phases

\begin{tabular}{|c|c|c|}
\hline $\begin{array}{l}\text { Exploration } \\
\text { phase }\end{array}$ & Examples of activity & Classification \\
\hline $\begin{array}{l}\text { Phase I } \\
\text { (Desktop study) } \\
\text { Conceptual } \\
\text { targets }\end{array}$ & 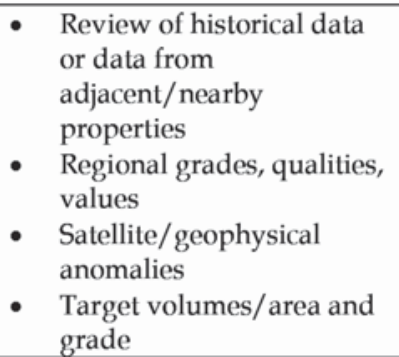 & $\begin{array}{l}\text { Exploration Target } \\
\text { - Insufficient data and/or } \\
\text { confidence levels to estimate a } \\
\text { Resource } \\
\text { - Need to present all data } \\
\text { (volume, area, tonnage, grade } \\
\text { and value) as ranges and } \\
\text { approximations, with } \\
\text { cautionary statements }\end{array}$ \\
\hline $\begin{array}{l}\text { Phase II } \\
\text { (Reconnaissance } \\
\text { exploration) }\end{array}$ & $\begin{array}{ll}\text { - } & \text { Reconnaissance drilling } \\
\text { and/or / pitting } \\
\text { - } \\
\text { - } \text { Keconnaissance sampling } \\
\text { mineralitic indicator } \\
\text { - Reconnistry } \\
\text { sampling }\end{array}$ & $\begin{array}{l}\text { - Cannot be included in Mineral } \\
\text { Resource Statements or Tables } \\
\text { - Cannot be included in technical } \\
\text { studies or economic } \\
\text { assessments } \\
\text { - Cannot be included in DCF } \\
\text { valuations }\end{array}$ \\
\hline $\begin{array}{l}\text { Phase III } \\
\text { Resource } \\
\text { estimation }\end{array}$ & $\begin{array}{l}\text { - Systematic drilling/pitting } \\
\text { - Sampling / bulk-sampling }\end{array}$ & $\begin{array}{l}\text { Mineral Resource } \\
\text { Reasonable prospects for } \\
\text { eventual economic extraction } \\
\text { have been demonstrated } \\
\text { - Sufficient data and confidence } \\
\text { levels to classify the Resource }\end{array}$ \\
\hline
\end{tabular}




\section{Exploration Results, Exploration Targets, and Mineralisation}

A number of case studies might be considered, which will help to highlight the differences between conceptual Exploration Targets and Mineralisation. Irrespective of the commodity and/or mineralisation type described in the specific case study, the principles are applicable to all commodity and deposit types.

\section{Examples}

\section{Case study 1}

BHP Billiton, as one of the largest mining companies in the world, is committed to developing large, long-life, low-cost expandable operations. An appreciation of this long-term potential in the earliest stages of development is critical for profitable long-term investment. To estimate this long-term potential, the company has developed a rigorous in-house method to assess the mineral endowment potential of a province that is unconstrained by current markets, technology, and the detailed requirements for Resource classification. Exploration Targets (potential mineralisation) are estimated from a limited set of geological information and are reported as a range to reflect different interpretations and the higher level of geological uncertainty. The geological information can be a combination of geophysical, mapping, and sampling data. Such targets (Mullins et al., 2014) capture the essence of 'what we think will be there when the area under consideration is fully explored' and contribute to the total mineral inventory to consider and prioritize longterm development options for a given orebody or mineral province.

\section{Case study 2}

The Midamines Concession is located along the Kwango River in the Democratic Republic of Congo (DRC). Diamonds have long been associated with alluvial sediments within this river system both in Angola and the DRC. Historical data (primarily pre-1980s) regarding diamond recoveries covers an area of some $600 \mathrm{~km}$, both up- and downstream of the project concession; however, no formal resource statements compatible with any international code were ever issued. Major prospecting/mining activity in this area ceased after independence in 1960, although low-level artisanal activity continued in various locations along the river, and even on the concession itself.

A site visit confirmed that extensive river, flats were located on each side of a meandering river as well as the presence of several levels of higher terraces. An interpretation of available satellite data suggested that some $50 \mathrm{~km}^{2}$ (river channel, floodplain, and terrace) was potentially underlain by gravels. Information gleaned from the artisanals operating on the site indicated that the basal gravels in the present river bed (the primary target) were some $1 \mathrm{~m}$ thick. Limited information was also obtained regarding average diamond size and sales value. The only formal mining activity in the Kwango valley was located some $135 \mathrm{~km}$ upstream in a different geomorphological setting. A resource statement from this operation was obtained for comparison.

At this stage of knowledge, the first Public Report on the property identified an (early stage, conceptual) Exploration Target of approximately 8-10 $\mathrm{Mm}^{3}$ in the present river and an additional $35-40 \mathrm{~km}^{2}$ of abandoned river channel, floodplain, and terrace deposits (De Decker, 2005). Target grades for the Kwango River (and, therefore the project property) are 0.8-1-5 carats per cubic metre (ct/m3) and average sales values in the region of US\$90-140 per carat.

For the sake of the example, if it is assumed that the company proceeded to prospect this property; that a number of bulk sample pits were excavated on the floodplains and terraces and a small dredge was installed on the river itself; also a RC drill-rig was employed to drill on a wide grid spacing (as defined in the exploration programme outlined in the abovementioned geological report). As a result of this programme, $250 \mathrm{ct}$ of diamonds were recovered and valued at US\$120 per carat. The next Public Report or news release, if done in accordance with the 2016 SAMREC Code, would indicate that Mineralisation (no longer simply a concept) had been identified on the property in the amount of some 8.5$9.5 \mathrm{Mm}^{3}$ of gravel in the present river and approximately 36$38 \mathrm{Mm}^{3}$ in the floodplain/terrace environment, at sample grades of $0.8-1 \mathrm{ct} / \mathrm{m}^{3}$ and an average diamond value of around US\$90-140 per carat. The news release would not have the headline ' $47.5 \mathrm{Mm}^{3}$ of diamondiferous gravel identified on the Midamines Concession'.

\section{Case study 3}

A number of kimberlite dykes are known to exist on the Bobi concession in Côte d'Ivoire. Volumes were estimated from drilling during 1993-1995 - the exact locations of the holes as well as the original core were destroyed during the civil war of 1999-2011. It is unknown how much material was processed from the different kimberlites over the years or how many diamonds were recovered. Historical documents indicate anecdotal grades of $0.15-0.3 \mathrm{ct} / \mathrm{m}^{3}$ based on the recovery of an unknown number of carats from an unknown volume of material by artisanals. Diamond values are based on a report by Reuters (in 2014) which indicates that before the embargo, some 300000 ct a year were being exported from the Ivorian diamond fields, worth around US\$25 million (estimated US\$83 per carat). Current sales (by small-scale artisanals) to local diamond buyers indicate prices of some US\$50-200 per carat

On the same property, a detailed ground geophysical survey (magnetics) was completed during 1974. Seven geophysical targets were identified from this data. No drilling has taken place to confirm whether they represent kimberlite.

Based on this information, this project may be classified as containing identified Mineralisation as well as conceptual Exploration Targets. With respect to the Mineralisation, although some useful information is available from sampling on the property itself, it is totally inadequate to be stated as a Resource (Marshall, 2014). In addition, RPEEE have not been demonstrated at any scale. In a Public Report, a statement might indicate the identification of Mineralisation of some $300000-400000 \mathrm{~m}^{3}$ of kimberlite to a depth of $60 \mathrm{~m}$ at sample grades of $0.15-0.3 \mathrm{ct} / \mathrm{m}^{3}$ and US $\$ 50-200$ per carat.

The geophysical anomalies, while occurring on the property, spatially related to the known kimberlites, and having similar (geophysical) characteristics, have not yet been verified as representing kimberlite. These anomalies have geological merit and would be classified as conceptual Exploration Targets. Again, the news release might indicate that the company is pursuing kimberlitic Exploration Targets with a combined volume in excess of $500000 \mathrm{~m}^{3}$, where regional grades and values are in the range of $0.15-0.3 \mathrm{ct} / \mathrm{m}^{3}$ and US\$50-200 per carat. 


\section{Exploration Results, Exploration Targets, and Mineralisation}

\section{Case study 4}

A company holds rights to a chrome project in the eastern limb of the Bushveld Complex. The project area is covered by recent sediments, with minimal outcrop of the underlying geology. The regional and local geology is well known, with current activity on nearby properties - one is an underground mining operation with identified Mineral Resources and Mineral Reserves; and another project (adjacent to the project property), has been the subject of recent exploration,

No historical mining has been known on the project property and the only documented historical exploration is for adjacent projects, including two percussion boreholes that were drilled into the suboutcrop area (LG6 chromitite unit) near the southern boundary of the farm. An initial exploration programme was conducted by the company, which included an aeromagnetic survey (including $5 \mathrm{~m}$ contours for a detailed digital terrain model), as well as the drilling of 10 diamond and reverse circulation drill-holes.

The regional geology of the Bushveld Complex is very well known and it might be tempting on the part of a $\mathrm{CP}$ to extrapolate a Mineral Resource based on limited data from the property itself. In this case, the limited exploration borehole information and geophysical data, combined with extensive regional information resulted in the $\mathrm{CP}$ declaring an Exploration Target (Clay et al., 2014). The provisions of the 2016 SAMREC Code would add that the Exploration Target could be further described as Mineralisation.

\section{Conclusions}

SAMREC (and other CRIRSCO codes) adequately addresses the consistent approach required to evaluate and report the nature and extents of potentially economic Mineral Resources. However, limited guidelines exist for the Public Reporting of material that cannot be described as a Mineral Resource. As a result of these inadequacies, many junior/private exploration companies have misused and abused the Resource classification category (especially the Inferred Mineral Resource category). In an attempt to prevent such abuse and regulate the reporting of the pre-resource space, the 2016 SAMREC Code has greatly expanded on the concept of Exploration Targets - what they may include and how they may be reported in the public domain in a manner that is not misleading, but is useful for potential investors and other stakeholders, in assessing the exploration potential of a specific property of even of an entire mineral province.

The term 'Mineralisation' is introduced as a variety of Exploration Target where the target is no longer purely conceptual, but where actual data has been obtained on the property and where mineralisation has been identified (based on actual Exploration Results). It refers to the situation where insufficient exploration data has been acquired to estimate a Mineral Resource, where the existing data is of insufficient confidence to allow the classification of a Mineral Resource or where reasonable prospects for eventual economic extraction (RPEEE) have not yet been demonstrated.

When discussing Exploration Targets (either conceptual or with identified Mineralisation), the $\mathrm{CP}$ must clearly describe the rationale for such selection, including the geological model on which it is based. Any statement referring to potential quantity, quality, and content, as appropriate, must be substantiated and include a detailed explanation of the basis for the statement. This must be followed by a proximate statement, with the same prominence, that the potential quantity, quality, and content, as appropriate, are conceptual in nature, that there has been insufficient exploration to define a Mineral Resource, and that it is uncertain if further exploration could result in the determination of a Mineral Resource.

Exploration Targets (conceptual or with identified Mineralisation) may not be included in a Technical Study (at Scoping, Pre-Feasibility, or Feasibility level) and may not be converted to Mineral Reserves. They may not be included in economic assessments or discounted cash flow (DCF) models, nor be included in valuations based on Income Approaches. Given the levels of uncertainty surrounding the supporting data, the quantity (volume or tonnage) or quality (grade and value) of an Exploration Target may not be reported as a 'headline statement' in a Public Report.

It is apparent that, in each of the examples or case studies presented, the Exploration Targets have merit, based on their regional setting, association with known deposits and/or limited prospecting data. However, the paucity of sample data, lack of confidence in the data or lack of demonstrated RPEEE means that they cannot be classified as Mineral Resources.

\section{References}

CIM. 2014. Definition Standards for Mineral Resources and Mineral Reserves 2014. Prepared by the Standing Committee on Reserve Definitions. Adopted by CIM Council on 10 May 2014.

http://www.cim.org/ /media/Files/PDF/Subsites/CIM_DEFINITION_STAND ARDS_20142

CIM. 2011. Companion Policy 43-101CP to National Instrument 43-101 Standards of Disclosure for Mineral Projects.

http://web.cim.org/standards/documents/Block484_Doc111.pdf

Clay, A.N., Orford, T.C., Dyke, S., Myburgh, J.A., and Mphahlele, K. 2014 Independent Competent Persons' Report on the Moeijelik Chromite Mineral Asset prepared for Bauba Platinum Limited. Venmyn Deloitte, Johannesburg.

DE DeCKER, R.H. 2005. Report on a field visit to the Midamines Concession on the Kwango River, DRC to assess the potential for Diamond Mining. De Decker and Associates Consulting Services, Noordhoek.

JORC. 2012. Australasian Joint Ore Reserves Committee. Australasian Code for Reporting of Exploration Results, Mineral Resources and Ore Reserves. The Joint Ore Reserves Committee of the Australasian Institute of Mining and Metallurgy, Australian Institute of Geoscientists, and Minerals Council of Australia. http://www.jorc.org/docs/JORC_code_2012.pdf

MARShall, T.R. 2014. Desktop study of the Bobi Diamond Project, Seguela, Cote d'Ivoire. Explorations Unlimited, Johannesburg.

Mullins, M., Hodkiewicz, P., McCluskey, J., CARey, C., and Terry, J. 2014. Estimating and reporting potential mineralisation at BHP Biliton - the unconstrained view. Monograph Series 30. Australasian Institute of Mining and Metallurgy, Melbourne. pp. 791-798.

PERC. 2013. Pan-European Reserves and Resources Reporting Committee PERC Reporting Standard 2013. Pan European Standard for Reporting of Exploration Results, Mineral Resources and Reserves ('The PERC Reporting Standard'). 15 March 2013 (revision 2: 29 November 2013). http://www.vmine.net/PERC/documents/PERC_REPORTING_STANDARD 2013_rev2.pdf http://www.vmine.net/PERC/documents/PERC_REPORTING_STANDARD 2013_rev2.pdf

SME. 2014. The Resources and Reserves Committee of the Society for Mining, Metallurgy and Exploration, Inc. The SME Guide for reporting Exploration Results, Mineral Resources and Mineral Reserves. June 2014. Society for Mining, Metallurgy and Exploration Inc., Englewood, CO. 